\title{
Austin moore vs bipolar prosthesis in management of intracapsular fracture of neck of femur by hemiarthroplasty
}

\author{
Nathi A.K., Sarma S. B.
}

${ }^{1}$ Dr. Anil Kumar Nathi, Assistant Professor, Department of Orthopaedics, Great Eastern Medical School and Hospital, Ragolu, Andhra Pradesh, India, ${ }^{2}$ Dr. Sista Baladitya Sarma, Senior Resident, Department of Orthopaedics, Andhra Medical College, Visakhapatnam, Andhra Pradesh, India.

Corresponding Author: Dr. Sista Baladitya Sarma, Department of Orthopaedics, Andhra Medical College, Visakhapatnam, Andhra Pradesh, India. E-mail: adityasista1@gmail.com

\begin{abstract}
Introduction: Fracture neck of femur is one of the widely occurring hip fractures among elderly people in India. They greatly affect the quality of life in patients, and $30 \%$ mortality is observed in these fractures. This study was carried out to study the profile of fracture neck of femur presenting to a tertiary care teaching hospital. The study also assessed functional outcome differences between Austin Moore and bipolar hip prosthesis used in hemiarthroplasty. Methods: The present prospective study includes 50 cases of intracapsular fracture neck of femur in elderly patients above the age of 55 years irrespective of sex treated by hemiarthroplasty using unipolar (Austin Moore's) or bipolar(nonmodular) endoprosthesis followed up for 6 months. After surgery, all the cases were followed up. The functional results after hemiarthroplasty were analyzed using Harris Hip Score (HHS). Results: The mean age was 63.14 \pm 5.66 in AMP, and it was $63.29 \pm 4$ in bipolar prosthesis. The other baseline parameters were comparable between the groups. The mean Harris hip score was $83.19 \pm 10.94$ in AMP, and it was $84.62 \pm 9.53$ in bipolar prosthesis. The difference was statistically not significant ( $\mathrm{P}$ value 0.654$)$. A higher percentage of patients, about $43 \%$ were found to have good functional outcome with bipolar prosthesis than those with Austin Moore prosthesis whose percentage having fair outcome was found to be $19 \%$. However, no significant difference was seen between the groups. Conclusion: Treatment outcomes were similar between the two groups.
\end{abstract}

Keywords: Austin Moore, Bipolar Prosthesis, Fracture neck of femur, Hemiarthroplasty, Prosthesis

\section{Introduction}

Hip fractures in the elderly, mainly caused due to osteoporosis, are one of the serious fractures because of associated morbidity and mortality. These fractures are being recognised as one of the growing health problems among elderly people in Asia [1]. Simple fall which can be described as low energy trauma also may cause severe hip fractures due to osteoporosis in elderly people particularly females. Hip fractures are broadly classified into intra, and extracapsular fracture neck of femur based on location of fracture at the hip joint [2]. Hip fractures, particularly in elderly people have detrimental effect on all aspects of their life. Health-related quality of life (HRQoL) was found to be impaired in first 3 months after a hip fracture.

Though improvement was noticed in HRQoL over a period of time it did not return to pre-fracture levels in most of the patients [3]. Effect of hip fracture on daily activities and quality of life is found to be more

Manuscript Received: $16^{\text {th }}$ October 2019

Reviewed: $26^{\text {th }}$ October 2019

Author Corrected: $4^{\text {th }}$ November 2019

Accepted for Publication: $8^{\text {th }}$ November 2019 detrimental in patients who live in unfavourable socioeconomic conditions.It was observed that impairment in Quality of life was not different in different types of hip fractures [4]. Studies show that one out of two previously independent people become partially dependant and every third person became dependent after hip fracture [5]. It was observed that in patients had more negative effect on quality of life in a hip fracture [6].

Multiple surgical treatment options are available for the treatment of intracapsular fracture neck of femur, and these are preferred over non-operative treatment procedures because of failures observed in non-surgical fixations [7]. Though best treatment option depends on condition of the patient many studies have established hemiarthroplasty to be the best treatment option among all the available options because of good functional outcome and good results in terms of mobility [8]. In hemiarthroplasty unipolar or bipolar prosthesis can be used as an implant, but many studies have demonstrated certain disadvantages associated with usage of unipolar 


\section{Original Research Article}

prosthesis. The disadvantages encountered using unipolar prosthesis include high acetabular erosion and protrusion which have shown to be overcome by using bipolar prosthesis [9]. The bipolar prosthesis has been shown to decrease acetabular erosion because of presence of two bearing surfaces. The polyethylene inner bearing reduces magnitude of forces between implant and acetabulum [9].

This increased advantages of the use of bipolar prosthesis have been reported by many studies. The percentage of unsatisfactory results in using unipolar prosthesis varied from $13 \%$ to $48 \%$ in various studies. Jadhav et al [10], in their review of patients undergoing Austin Moore replacement found higher satisfactory results in patients over 70 years of age who have low activity level. In patients less than 65 years of age with high activity level the results were unsatisfactory with incidence of postoperative pain. Andersson et $\mathrm{al}[11]$, in their study on prosthesis in femoral fractures found only $6 \%$ of patients using unipolar prosthesis walking without a limp. A study Whittaker et al [12] showed acetabular protrusion in 5\% patients and narrowing in $25 \%$ patients after $1-4$ years of hip arthroplasty, after 5 years protrusion was noticed in $24 \%$ of patients and narrowing was noticed in $64 \%$ of patients. Arthroplasty is mainly performed in patients to avoid non-union of fractures and avascular necrosis which is noticed in internal fixation. Several studies have established that arthroplasty results in better functional outcome when compared to internal fixation [13]. Total hip arthroplasty and hemiarthroplasty are two types of arthroplasty procedures that can be used for displaced femoral neck fractures, but studies comparing these two procedures are less conclusive.

Review of recent hip fracture surgical trends show increased usage of hemiarthroplasty which may be because of lack of clear established superiority of total hip replacement over hemiarthroplasty and hemiarthroplasty is technically easy to perform particularly in less active elderly patients [13]. The focus of this study is on intracapsular hip fracture and its treatment. To study the profile of fracture neck of femur presenting to a tertiary care teaching hospital. The study also assessed functional outcome differences between Austin Moore and bipolar hip prosthesis used in hemiarthroplasty.

\section{Materials and Methods}

Study setting: The study was conducted on patients with intracapsular fracture of neck of femur in elderly patients

Study design: The current study was a prospective study.

Study period: The study was conducted between December 2018 to June 2019.

Sample size: The present prospective study includes 50 cases of intracapsular fracture neck of femur in elderly

Surgical Update: International Journal of Surgery \& Orthopedics patients above the age of 55 years irrespective of sex treated by hemiarthroplasty using unipolar (Austin Moore's) or bipolar(nonmodular) endoprosthesis

Inclusion criteria: The study had included, all the adult patients ( $>55$ years), of both genders, undergoing surgery for intracapsular fracture at neck of femur and treated by hemiarthroplasty using unipolar (Austin Moore's) or bipolar(nonmodular) endoprosthesis.

Exclusion criteria: 1). Patients with dementia, 2). Patients who were nonambulatory 3) Patients with pathological femoral neck fracture and 4) Patients with additional acute lower extremity fractures in addition to the femoral neck fracture.

Preoperative Management: Patients were admitted to the ward. A detailed history was taken with particular emphasis on mode of injury and associated medical illness. In-depth, clinical assessment was carried out in each case. In all patients preoperatively, skin traction with appropriate weight was applied to the fractured lower limb, with the aim of relieving pain preventing shortening and to reduce unnecessary movements of the injured limb.

Oral or parenteral NSAIDs were given to relieve the pain. Antero posterior radiographs of the affected hip joint of pelvis with both hips were taken for all the patients, keeping the fractured limb in $15^{\circ}$ internal rotation to bring the neck parallel to X-ray film. Routine blood investigations, blood grouping and typing, urine routine, RBS, serum urea, creatinine, HbsAg, HIV, chest x-ray, ECG, were done in all cases. Certain therapeutic exercises were taught pre-operatively to the patients who had to be continued post-operatively, such as deep breathing exercises, static quadriceps exercises, ankle movements.

Patients, as well as the attenders, were explained about the surgery, and its risk factors and written consent for the surgery was taken for all patients. Intravenous antibiotics and tetanus immunization were given an hour before the surgery. The limb was prepared from nipple to knee including perineum and back.

Data collection procedure: The study was carried out to evaluate the immediate and early results of hemiarthroplasty for intracapsular fracture of neck of femur in elderly. Operations were performed by different levels of faculty after the patient agreed to the treatment. Fifty cases treated by hemiarthroplasty were followed up for 6 months. After surgery, all the cases were followed up. The functional results after hemiarthroplasty are therefore analysed for fifty patients. Once the patient was admitted to the hospital, all the essential information was recorded in the proforma prepared for this study. They

Available online at: www.medresearch.in 315 | P a g e 
were observed regularly during their hospital stay till discharge. Follow-up Hip ROM, Harris hip score, Functional results and outcome were determined.

Ethical consideration \& permission: The study was approved by Institutional Human ethical committee and informed written consent was obtained from all the participants. Confidentiality of the study participants was maintained throughout the reporting of study results.

Data analysis: Side, mode of injury, type of Gardens Class, Other injuries, Follow-up Hip ROM, Harris hip score and Functional results \& outcome were considered

\section{Original Research Article}

as primary outcome variables. Age and gender were considered study relevant variables. Type of prosthesis was considered as primary explanatory variable. For normally distributed Quantitative parameters the mean values were compared between study groups using Independent sample t-test (2 groups).

Data was also represented using appropriate diagrams like box plots. Categorical outcomes were compared between study groups using Chi square test. $\mathrm{P}$ value $<0.05$ was considered statistically significant. IBM SPSS version 22 was used for statistical analysis [14].

\section{Result}

A total of 42 subjects were included in the final analysis.

The mean age was $63.14 \pm 5.66$ in AMP, and it was $63.29 \pm 4$ in bipolar prosthesis. The difference in the age between type of prosthesis was statistically not significant (P value 0.925). Among the AMP, 9 (42.86\%) were male, and 12 (57.14\%) were female. Among the bipolar prosthesis, $10(47.62 \%)$ were male, and $11(52.38 \%)$ were female. The difference in the proportion of gender between type of prosthesis was statistically not significant ( $\mathrm{P}$ value 0.757$)$. Among the AMP, 12 (57.14\%) had left side, and 9 (42.86\%) had right side. Among the bipolar prosthesis, $13(61.9 \%)$ had left side, and $8(38.1 \%)$ had right side. The difference was statistically not significant (P value 0.753). Among the AMP, 2 (9.52\%) were with RTA side, and 19 (90.48\%) were with Trivial trauma. Among the bipolar prosthesis, 2 (9.52\%) were with RTA side, and 19 (90.48\%) were with Trivial trauma. The difference was statistically not significant (P value 1.000) (Table 1).

Among the AMP, 7 (33.33\%) had gardens class II fracture, 8 (38.1\%) had gardens class III, and 6 (28.57\%) had gardens class IV. Among the bipolar prosthesis, 5 (23.81\%) had gardens class II fracture, 8 (38.1\%) had gardens class III, and 8 (38.1\%) had gardens class IV. The difference in the proportion was statistically not significant (P value 0.734) (Table 2).

Among the AMP, $1(4.76 \%)$ had abrasions, 1 (4.76\%) had a clavicle fracture, $1(4.76 \%)$ had left colles fracture, and $1(4.76 \%)$ had old fracture neck of femur. Among the bipolar prosthesis, 2 (9.52\%) had abrasions, and 1 (4.76\%) had laceration (Table $3)$.

Table-1: Comparison of mean of age between the type of prosthesis $(N=42)$

\begin{tabular}{|c|c|c|c|}
\hline \multirow[b]{2}{*}{ Parameter } & \multicolumn{2}{|c|}{ Type of Prosthesis } & \multirow[b]{2}{*}{$P$ value } \\
\hline & $\begin{array}{c}\operatorname{AMP}(\mathbf{N}=21) \\
(\text { Mean } \pm \text { SD })\end{array}$ & $\begin{array}{c}\text { Bipolar }(\mathbf{N}=21) \\
(\text { Mean } \pm \text { SD) }\end{array}$ & \\
\hline Age & $63.14 \pm 5.66$ & $63.29 \pm 4$ & 0.925 \\
\hline \multicolumn{4}{|l|}{ Gender } \\
\hline Male & $9(42.86 \%)$ & $10(47.62 \%)$ & \multirow{2}{*}{0.757} \\
\hline Female & $12(57.14 \%)$ & $11(52.38 \%)$ & \\
\hline \multicolumn{4}{|l|}{ Side } \\
\hline Left & $12(57.14 \%)$ & $13(61.9 \%)$ & \multirow{2}{*}{0.753} \\
\hline Right & $9(42.86 \%)$ & $8(38.1 \%)$ & \\
\hline \multicolumn{4}{|l|}{ Side } \\
\hline RTA & $2(9.52 \%)$ & $2(9.52 \%)$ & \multirow{2}{*}{1.000} \\
\hline Trivial trauma & $19(90.48 \%)$ & $19(90.48 \%)$ & \\
\hline
\end{tabular}


Original Research Article

Table-2: Comparison of type of \# gardens class between the type of prosthesis $(\mathrm{N}=42)$

\begin{tabular}{|c|c|c|c|c|}
\hline \multirow{2}{*}{$\begin{array}{c}\text { Type of gardens } \\
\text { class. }\end{array}$} & \multicolumn{2}{|c|}{ Type of Prosthesis } & \multirow{2}{*}{ Chi square } & \multirow{2}{*}{ P value } \\
\cline { 2 - 3 } & AMP (N=21) & Bipolar (N=21) & & \\
\hline II & $7(33.33 \%)$ & $5(23.81 \%)$ & 0.619 & 0.734 \\
\hline III & $8(38.1 \%)$ & $8(38.1 \%)$ & \\
\hline IV & $6(28.57 \%)$ & $8(38.1 \%)$ & & \\
\hline
\end{tabular}

Table-3: Comparison of other associated injuries between the type of prosthesis $(\mathrm{N}=42)$

\begin{tabular}{|c|c|c|}
\hline \multirow{2}{*}{ Other Injuries } & \multicolumn{2}{|c|}{ Type of Prosthesis } \\
\cline { 2 - 3 } & Amp (N=21) & Bipolar (N=21) \\
\hline Abrasions & $1(4.76 \%)$ & $2(9.52 \%)$ \\
\hline Clavicle fracture & $1(4.76 \%)$ & $1(4.76 \%)$ \\
\hline Laceration & $0(0 \%)$ & $0(0 \%)$ \\
\hline Left colles fracture & $1(4.76 \%)$ & $18(85.71 \%)$ \\
\hline Nil & $17(80.95 \%)$ & $0(0 \%)$ \\
\hline
\end{tabular}

* No statistical test was applied-due to 0 subjects in the cell

Table-4: Comparison of follow-up total hip rom between the type of prosthesis $(\mathrm{N}=42)$

\begin{tabular}{|c|c|c|c|c|}
\hline \multirow{2}{*}{$\begin{array}{c}\text { Follow-up } \\
\text { Total Hip Rom }\end{array}$} & \multicolumn{2}{|c|}{ Type of Prosthesis } & \multirow{2}{*}{ Chi square } & \multirow{2}{*}{ P value } \\
\hline & $\operatorname{Amp}(\mathrm{N}=21)$ & Bipolar $(\mathrm{N}=21)$ & & \\
\hline $101-160^{0}$ & $3(14.29 \%)$ & $3(14.29 \%)$ & \multirow{3}{*}{0.114} & \multirow{3}{*}{0.944} \\
\hline $161-210^{0}$ & $10(47.62 \%)$ & $11(52.38 \%)$ & & \\
\hline $211-300^{0}$ & $8(38.1 \%)$ & $7(33.33 \%)$ & & \\
\hline
\end{tabular}

Table-5: Comparison of mean of Harris hip score between the type of prosthesis $(\mathrm{N}=42)$

\begin{tabular}{|c|c|c|c|}
\hline \multirow{2}{*}{ Parameter } & \multicolumn{2}{|c|}{ Type of Prosthesis } & \multirow{2}{*}{ P value } \\
\cline { 2 - 4 } & $\begin{array}{c}\text { AMP }(\mathbf{N}=\mathbf{2 1}) \\
(\text { Mean } \pm \text { SD) }\end{array}$ & $\begin{array}{c}\text { Bipolar }(\mathbf{N}=\mathbf{2 1}) \\
\text { (Mean } \pm \text { SD) }\end{array}$ & \\
\hline Harris hip score & $83.19 \pm 10.94$ & $84.62 \pm 9.53$ & 0.654 \\
\hline
\end{tabular}

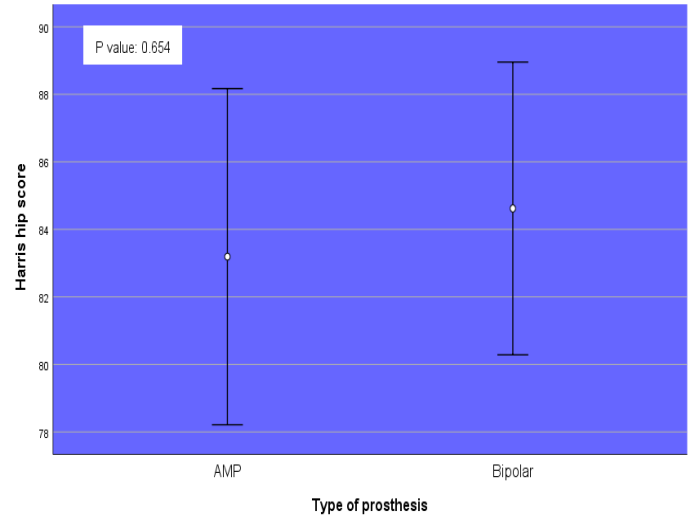

Figure-1: Bar chart of the mean of Harris hip score between type of prosthesis $(\mathrm{N}=42)$ 
Original Research Article

Table-6: Comparison of functional results \& amp; outcome between the type of prosthesis $(\mathrm{N}=42)$

\begin{tabular}{|c|c|c|c|c|}
\hline \multirow{2}{*}{$\begin{array}{c}\text { Functional Results \& } \\
\text { Amp; Outcome }\end{array}$} & \multicolumn{2}{|c|}{ Type of Prosthesis } & \multirow{2}{*}{ Chi square } & \multirow{2}{*}{ P value } \\
\cline { 2 - 3 } & Amp (N=21) & Bipolar (N=21) & & \\
\hline Excellent & $8(38.1 \%)$ & $7(33.33 \%)$ & \multirow{2}{*}{3.190} & 0.363 \\
\hline Good & $4(19.05 \%)$ & $9(42.86 \%)$ & \\
\hline Fair & $6(28.57 \%)$ & $3(14.29 \%)$ & & \\
\hline Poor & $3(14.29 \%)$ & $2(9.52 \%)$ & & \\
\hline
\end{tabular}

Among the AMP, 3 (14.29\%) participants had to follow - up total hip rom of $101-160^{\circ}, 10(47.62 \%)$ participants had rom of $161-210^{0}$, and $8(38.1 \%)$ had rom of $211-300^{\circ}$. Among the bipolar prosthesis, $3(14.29 \%)$ participants had follow-up total hip rom of $101-160^{\circ}, 11(52.38 \%)$ had rom of $161-210^{\circ}$, and $7(33.33 \%)$ had $211-300^{\circ}$. The difference was statistically not significant (P value 0.944). (Table 4)

The mean Harris hip score was $83.19 \pm 10.94$ in AMP, and it was $84.62 \pm 9.53$ in bipolar prosthesis. The difference in the Harris hip score between type of prosthesis was statistically not significant (P value 0.654). (Table 5 \& Figure 1 )

Among the AMP, 8 (38.1\%) had excellent functional results \& Amp; outcome, 4 (19.05\%) had good functional results \& Amp; outcome, 6 (28.57\%) had fair functional results \& Amp; outcome and 3 (14.29\%) had poor functional results \& Amp; outcome. Among the bipolar prosthesis, 7 (33.33\%) had excellent functional results \& Amp; outcome, 9 (42.86\%) had good functional results \& Amp; outcome, 3 (14.29\%) had fair functional results \& Amp; outcome and 2 (9.52\%) had poor functional results \& Amp; outcome. The difference in the proportion of functional results \& Amp; outcome between the type of prosthesis was statistically not significant (P value 0.363 ). (Table 6)

\section{Discussion}

Increased longevity has increased health complications associated with old age globally. India also has witnessed an increased burden of old age-associated health problems, and hip fractures are one of them. The disability caused by hip fractures and adverse effect of hip surgery has made hip fractures an important area of public concern [15]. Based on these factors and to fill in the lacunae of Indian studies on incidence of hip fractures, morbidity and mortality associated with most common surgical procedure used for treatment of hip fractures in elderly people this study was conducted on 50 cases of intracapsular fracture neck of femur in elderly patients above the age of 55 years irrespective of sex treated by hemiarthroplasty using unipolar (Austin Moore's) or bipolar(nonmodular) endoprosthesis, selected on the basis of purposive sampling (Judgment sampling) method.

The study was carried out to evaluate the immediate and early results of hemiarthroplasty for intracapsular fracture of neck of femur in elderly. In the current study, 38\% of patients were in the age group of 60-65 years, indicating higher incidence of hip fractures in this age group followed by $28 \%$ in age group of $65-70$ years. The frequency of hip fractures was seen more in older age group usually between $60-70$ years. It is obvious that the fracture increases in older age due to progressive loss of bone-muscle mass and strength.[16] Many literatures like the study by Sullivan, KJ et al[17], and another study by
Pillai, A et al[18], indicate increase in risk of hip fractures with increase in age but did not mention the age bracket. Decreased occurrence of hip fractures in elderly people aged above 70 years in this study can be attributed to two factors. One is a smaller number of study participants in this age group and second may be very less activity of people aged above 70 years making them less prone to fractures. Among the study population, $42 \%$ were participants male and remaining $58 \%$ participants were female. This increased percentage of female patients is in correlation with studies like study by Pillai A et al[18], which concluded Hip fractures are more common among females irrespective of age group. In a study by Lin $\mathrm{KB}$ et al[15], where the cumulative incidence and hospital course of Taiwanese with hip fractures were investigated it was found that the incidence of hip fractures in the elderly was about two times higher in women than in men.

The current study found that after hemiarthroplasty $68 \%$ participants total hospital stay was less than 20 days, $92 \%$ did not have any complications, 28\% participants had Slight pain, $10 \%$ participants had Mild pain, 2\% participants had Moderate pain, and 6\% participants had Marked pain., $42 \%$ participants were suffering from Slight Limping, 22\% participants were suffering from Moderate Limping, and 2\% participants were suffering from Severe Limping, 34\% participants were using Cane for long walks support and $12 \%$ participants were using Cane most of the time for support. $40 \%$ participants were walking for 


\section{Original Research Article}

unlimited distance, $36 \%$ participants were walking for 6 blocks distance, $10 \%$ participants were walking for $2-3$ blocks distance, and $14 \%$ participants were walking indoors only. Among the study population, 74\% participants were comfortably sitting in ordinary chair for $1 \mathrm{hr}, 20 \%$ participants were comfortably sitting on a highchair for $1 / 2$ hour, and $6 \%$ participants were Unable to sit comfortably. Among the study population, 74\% participants were Entering public transportation.

All these observations indicate good functional outcome in majority of patients after hemiarthroplasty similar to observed in studies like study by Daniel, $M$ et al[19], in which early functional outcome and complications of Austin Moore endoprosthesis in elderly patients above 60 years with fractured neck of femur was analyzed it was concluded that functional outcome of Austin Moore in elderly patients above 60 years with author: neck of femur was satisfactory in most of the cases with minimal morbidity. In a study by Kumar, $\mathrm{KH}$ et al[20], where the functional outcome of hemiarthroplasty in fracture neck of femur in addition to surgical responses in elderly patients was evaluated it was concluded that hemiarthroplasty for fractured neck of femur in elderly does provide early ambulation, good functional outcome, pain free joint with minimal complications without the need for revision surgery.

The results obtained for the comparison of Austin Moore prosthesis and bipolar prosthesis in this study did not indicate significant statistical differences. Among the AMP, 38.1\% had excellent functional results \& Amp; outcome, $19.05 \%$ had good functional results \& Amp; outcome, $628.57 \%$ had fair functional results \& Amp; outcome and $14.29 \%$ had poor functional results \& Amp; outcome. Among the bipolar prosthesis, 33.33\% had excellent functional results \& Amp; outcome, $42.86 \%$ had good functional results \& Amp; outcome, 14.29\% had fair functional results \& Amp; outcome and $9.52 \%$ had poor functional results \& Amp; outcome. No statistically significant difference was noticed in associated complications and Harris hip score as well between two prosthesis. The mean Harris hip score was $83.19 \pm 10.94$ in AMP, and it was $84.62 \pm 9.53$ in bipolar prosthesis.

This finding of almost equal results between two types of prosthesis is similar to that found in a study by Hedbeck, CJ et al[21], in which the outcome regarding hip function and health-related quality of life (HRQoL) in patients randomized to either a unipolar or bipolar hemiarthroplasty was analyzed it was found that Unipolar hemiarthroplasty and bipolar hemiarthroplasty appeared to produce equivalent clinical outcomes after one year. There were no significant differences between the groups regarding complications. The HHS scores were equal at

Surgical Update: International Journal of Surgery \& Orthopedics both follow-ups, but there was a trend towards better HRQoL in the bipolar hemiarthroplasty group at four months. In another study by Mathew, K et al [22], which compared functional outcome of unipolar and bipolar prosthesis no statistically significant difference was found between functional outcomes with respect to two prosthesis but some difference in incidence of complications was noted. The incidence of complications was found to be lower in group having bipolar prosthesis. In another study by Marcus, $\mathrm{R}$ et al [23], where the two types of prosthesis were compared it was noted that functional results of bipolar prosthesis were not significantly better than Austin Moore prosthesis. This observation is different from that was found in many studies comparing unipolar and bipolar prosthesis. In a study by Somashekar, SVK et al [24], which compared the outcome of unipolar with the bipolar prosthesis in geriatric patients the mean Harris hip score in bipolar and unipolar groups was $86.18 \pm 12.18$ and $79.79 \pm 15.55$, respectively $(\mathrm{p}=0.183)$; range of motion was $210.63 \pm 28.39$ and $181.58 \pm 37(\mathrm{p}=0.015)$ with bipolar and unipolar groups, respectively.

Functional activities were better in the bipolar group. Complications like painful hip, posterior dislocation, periprosthetic fracture and acetabular erosion were encountered in unipolar prosthesis. In another study by Vishwanath, $\mathrm{C}$ et al [25], in which efficiency of unipolar and bipolar prosthesis for the management of intracapsular fracture neck femur in elderly was compared, it was concluded that the use of a bipolar endoprosthesis in the management of displaced femoral neck fractures in the elderly was associated with better mean Harris hip score and incidence of complications were limited. In another study by Zacharia, B et al [26], which analysed anatomical and functional outcome in elderly patients, treated with unipolar/bipolar prosthesis for displaced fracture neck of femur Harris Hip Score was 60.64 and 70.84 for AMP and Bipolar group respectively at final follow up. There was no significant difference in pain score between the two groups. In another study by Naser, MA et al [27], in which efficiency of Austin Moore's prosthesis (AMP) and bipolar prosthesis for the management of intracapsular fracture neck femur in elderly patients was compared the modified Harris hip score was better with bipolar group as compared to AMP group. Functional activities like use of public transport were better with bipolar group.

Complications like acetabular erosion were rare in bipolar group as comparison to AMP group. In another study by Krishna, KS et al [28], efficiency of unipolar and bipolar prosthesis for the management of intracapsular fracture neck femur in elderly was compared use of a bipolar endoprosthesis was associated with better mean Harris hip score and incidence of complications was limited. 


\section{Original Research Article}

Limitations \& recommendations: One of the limitations of the study was a single centre study, with convenience sampling technique and limited sample size. The future studies must include randomized trial with adequate sample size to determine which prosthesis is better.

The results for two types of the prosthesis were observed without much time gap after surgery which limits the scope to record long term outcome differences between two prosthesis. This study recommends preventive measures to be adopted by elderly people in the age group of 60 to 70 years to avoid fractures. In the event of fracture occurrence hemiarthroplasty with bipolar prosthesis is recommended as the best treatment option.

\section{Conclusion}

The incidence of fracture neck of femur is more in female patients in the age group of 60-70 years in India. Hemiarthroplasty is a better treatment method for management of femoral fractures in elderly patients with good functional outcome and limited morbidity and mortality. No significant differences were noted in the study population for functional outcome and associated complications between the bipolar prosthesis and Austin Moore prosthesis. This may be because of less time lapse between surgery and noting down of results. The differences observed between two types prosthesis is seen usually 1 to 2 years after surgery in the form of acetabular erosion noted in unipolar prosthesis.

\section{What the study adds to the existing knowledge?}

AMP is distinct from the modern cement less modular porous-coated prosthesis. The use of bipolar endoprosthesis in the management of displaced femoral neck fractures in the elderly was considered to be a better option in elderly patients with fractured neck of femur. There is a lack of Randomized controlled trials and systematic reviews on this matter.

\section{Author's contribution}

Dr. Anil Kumar Nathi had conceptualizesed the study, prepared the study protocol, conducted the data collection, analysis and manuscript writing. He has verified all the drafts and approved the final draft. Dr Sista Baladitya Sarma had provided key inputs on methodology during protocol preparation, supported data compilation and analysis. He has also edited all the drafts and approved the final draft of the manuscript.

Funding: No funding sources

Conflict of interest: None declared

Ethical Approval: Not required
Acknowledgements: Authors acknowledge the technical support in data entry, analysis and manuscript editing by "Evidencian Research Associates."

\section{Reference}

1. Dhanwal DK, Dennison EM, Harvey NC, Cooper C. Epidemiology of hip fracture: Worldwide geographic variation. Indian J Orthop. 2011; 45(1):15-22. doi: 10. 4103/ 0019-5413.73656.

2. Fernandez MA, Griffin XL, Costa ML. Management of hip fracture. Br Med Bull. 2015;115(1):165-172. doi: 10. 1093/bmb/ldv036.

3. Amphansap T, Sujarekul P. Quality of life and factors that affect osteoporotic hip fracture patients in Thailand. Osteoporos Sarcopenia. 2018;4(4):140-144. doi: org/10. 1016/j. afos.2018.11.082.

4. Mendonça TM, Silva CH, Canto RS, Morales NM, Pinto RM, Morales RR. Evaluation of the health-related quality of life in elderly patients according to the type of hip fracture: femoral neck or trochanteric. Clinics (Sao Paulo). 2008; 63(5):607-612. doi: 10.1590/S1807-59322 008000500007.

5. Prasad JD, Varghese AK, Jamkhandi D, Chakraborty A, Rakesh P, Abraham VJ. Quality-of-life among elderly with untreated fracture of neck of femur: a community based study from Southern India. J Family Med Prim Care. 2013; 2(3):270-273. doi: 10. 4103/ 2249-4863. 120755 .

6. van de Ree CLP, Landers MJF, Kruithof N, de Munter L, Slaets JPJ, Gosens T, et al. Effect of frailty on quality of life in elderly patients after hip fracture: a longitudinal study. BMJ Open. 2019; 9(7): e025941. doi: 10.1136/ bmjopen- 2018-025941.

7. Marya SK, Thukral R, Singh C. Prosthetic replacement in femoral neck fracture in the elderly: results and review of the literature. Indian J Orthop. 2008;42(1):61-67. doi: 10. 4103/0019-5413.38583.

8. Mak YF, Li HYA, Lee QJ, Wong YC. Modular bipolar hemiarthroplasty for fracture neck of femur using contemporary cementing technique: Long-term results of a single design. J Orthop Trauma Rehabil. 2019;26(1):6773. doi: $10.1177 / 2210491719848759$.

9. Abdelkhalek M, Abdelwahab M, Ali AM. Bipolar versus fixed-head hip arthroplasty for femoral neck fractures in elderly patients. Strategies Trauma Limb Reconstr. 2011;6(1):1-6. doi: 10.1007/s11751-010-0100-1 
10. Jadhav AP, Kulkarni SS, Vaidya SV, Divekar MM, Suralkar SP. Results of Austin Moore replacement. J Postgrad Med. 1996;42(2):33-38.

11. Anderson LD, Hamsa WRJ, Waring TL. Femoral Head Prosthesis: Review of 350 Operations and Their Results. J Bone Joint Surg Am. 1964;46:1049-1065.

12. Whittaker R, Abeshaus M, Scholl H, Chung S. Fifteen years' experience with metallic endoprosthetic replacement of the femoral head for femoral neck fractures. J Trauma Acute Care Surg. 1972; 12(9):799-806. doi: 10.1097/ 00005373- 197209000-00009.

13. Jain NB, Losina E, Ward DM, Harris MB, Katz JN. Trends in surgical management of femoral neck fractures in the United States. Clin Orthop Relat Res. 2008;466 (12):3116-3122. doi:10.1007/s11999-008-0392-3

14. IBM Corp. Released 2013. IBM SPSS Statistics for Windows, Version 22.0. Armonk, NY: IBM Corp.

15. Lin KB, Yang NP, Lee YH, Chan CL, Wu CH, Chen $\mathrm{HC}$, et al. The incidence and factors of hip fractures and subsequent morbidity in Taiwan: An 11-year populationbased cohort study. PLoS One. 2018;13(2):e0192388. doi: 10.1371/journal.pone.0192388.

16. Ferrucci L, Baroni M, Ranchelli A, Lauretani F, Maggio M, Mecocci P, et al. Interaction between bone and muscle in older persons with mobility limitations. Curr Pharm Des. 2014;20(19):3178-3197. doi: 10.2174/13816 128113196660690 .

17. Sullivan KJ, Husak LE, Altebarmakian M, Brox WT. Demographic factors in hip fracture incidence and mortality rates in California, 2000-2011. J Orthop Surg Res. 2016;11(1):4. doi: 10.1186/s13018-015-0332-3.

18. Pillai A, Eranki V, Shenoy R, Hadidi M. Age related incidence and early outcomes of hip fractures: a prospective cohort study of 1177 patients. J Orthop Surg Res. 2011;6(1):5. doi: 10.1186/1749-799X-6-5.

19. Daniel M, Mohammed S, Francis A, William Y, Joseph K, Cornilius E. Early result of hemiarthroplasty in elderly patients with fracture neck of femur. Niger Med J. 2015; 56(1):64-68. doi: 10.4103/0300-1652.149174.

\section{Original Research Article}

20. Kumar KH, Paranjyothi J. Surgical and Functional Outcomes of Hemi Arthroplasty in Fracture Neck of Femur. J Evid Based Med Health Care. 2015;2(7):859-864

21. Hedbeck CJ, Blomfeldt R, Lapidus G, Törnkvist H, Ponzer S, Tidermark J. Unipolar hemiarthroplasty versus bipolar hemiarthroplasty in the most elderly patients with displaced femoral neck fractures: a randomised, controlled trial. Int Orthop. 2011; 35(11):1703-1711. doi: 10.1007/ s00264-011- 1213-y.

22. Mathew KC, Prashant VS, Sahaya J, R , Vishnu TP, Akhil J. Treatment of Femoral Neck Fractures: Unipolar Versus Bipolar Hemiarthroplasty at Sree Mookambika Institute of Medical Sciences. Int J Contemp Surg. 2016;4 (1): 150-154. doi: 10.5958/2321-1024.2016.00033.7.

23. Marcus R, Heintz J, Pattee A. Comparison of the Austin-Moore and Bipolar Hemiarthroplasty in the Treatment of Femoral Neck Fractures. J Orthop Trauma. 1989;3(2):173.

24. Somashekar, Krishna SV, Sridhara Murthy J. Treatment of femoral neck fractures: unipolar versus bipolar hemiarthroplasty. Malays Orthop J. 2013;7(2):611. doi: 10.5704/MOJ.1307.007.

25. Vishwanath C, Mummigatti SB. Comparative study between Austin Moore prosthesis and bipolar prosthesis in fracture neck of femur. Nat J Clin Orthop. 2017;1(2):53-61

26. Zacharia B, Inassi J, Subramaniyan D, Pacha S. Unipolar Austin Moore's Prosthesis Versus Cemented Bipolar Arthroplasty in Displaced Neck of Femur Fracture, in Elderly Patients. J Clin Diagn Res. 2018; 12(8).

27. Naser MA, Pathak R, Ahmad A. Superiority of fixed stem bipolar prosthesis over Austin Moore prosthetic in fracture neck femur. Int J Res Orthop. 2018;4(4):577-81. doi: http://dx.doi.org/10.18203/issn. 2455-4510. Int JRes Orthop 20182415.

28. Krishna KS, Rao DV, Reddy GR, Sangepu A. Comparative study between austin moore prosthesis and bipolar prosthesis in fracture neck of femur. J Evol Med Dent Sci. 2015;4(101):16605-16610. doi: 10.14260/jemds/ $2015 / 2477$.

\section{How to cite this article?}

Nathi A.K, Sarma S. B. Austin moore vs bipolar prosthesis in management of intracapsular fracture of neck of femur by hemiarthroplasty. Surgical Update: Int J surg Orthopedics.2019;5(5):314-321.doi:10.17511/ijoso.2019.i05.02 